The New Tyranny of Student Participation? Student voice and the paradox of strategic-active student-citizens

\author{
Ana Barbosa Mendes ${ }^{\mathrm{a} 1}$ and Daniel Hammett ${ }^{\mathrm{b} *}$ \\ ${ }^{a}$ Department of Psychology, University of Sheffield. Sheffield, United Kingdom; \\ ${ }^{b}$ Department of Geography, University of Sheffield, Sheffield, United Kingdom
}

Corresponding author contact details:

Department of Geography

The University of Sheffield

Sheffield S10 2TN

United Kingdom

Tel. +44 1142227956 .

Email: D.Hammett@sheffield.ac.uk

\footnotetext{
${ }^{1}$ Current affiliation: ITEC. Faculty of Psychology and Educational Sciences. KU Leuven. Belgium.
} 


\title{
The New Tyranny of Student Participation? Student voice and the paradox of strategic-active student-citizens
}

\begin{abstract}
Student in governance and decision-making has become ubiquitous in higher education, evolving from buzzword to orthodoxy. Student engagement measures have become instruments of quality control, with students expected to take an active role in shaping institutional policy and practice. In this paper, we argue that this ubiquity of demands for student engagement has served to hollow-out and depoliticise student voice practices drawing upon Cooke and Kothari's seminal (2001) work in development studies to ask whether student voice has become a new tyranny of participation? In developing this argument, we identify how students are expected to be both strategic, instrumental consumers and active citizens of their university. This results in the paradox of the strategic active student citizen.
\end{abstract}

Keywords: student participation, tyranny, student-citizens, student voice

Word count: 6174 


\section{Introduction}

Student engagement has become a ubiquitous concern within higher education policy and practice. Despite this ubiquity, critics have argued that while literature reflects upon and advocates various forms of student engagement, the concept remains ill-theorised. In practice, student engagement is deployed in multiple, and often amorphous and nebulous ways as universities implement a myriad of policies to promote student participation throughout the degree experience (Buckley, 2014; Macfarlane and Tomlinson, 2017).

Student engagement policies are often deployed in connection to both governance and pedagogy (Buckley, 2014), with the term 'student voice' used to refer to the area of student participation in governance, quality assurance and development practices. The mechanisms for this vary dramatically, from passive, inauthentic forms of participation through to more active, authentic forms of engagement (Wimpenny and Savin-Baden, 2013). Our concern here is not with 'best' or 'better' ways of promoting meaningful engagement for governance and quality assurance, but to ask a more fundamental question: has the ubiquity of demands for student voice served to hollow-out and depoliticise these practices? Borrowing from development studies literature (see Cooke and Kothari, 2001), has the received wisdom of - and demand for - student participation/voice become a new tyranny?

In making this proposition, we acknowledge that student engagement is a broad concept deployed to discuss styles of learning and pedagogical approaches to stimulate active learning, reflect on modes and levels of attendance, as well as the role of students in learning and teaching governance. In this paper we are specifically concerned with student participation as linked to learning and teaching governance - the realm of student voice. The growing emphasis on the student-as-consumer in higher education policy and practice in the UK (Tight, 2013) and use of 'student voice' as a metric within the Teaching Excellence Framework (TEF) means 
that demands for student participation in the design and development of curricula and quality assurance mechanisms, are becoming omnipresent.

This article has been prompted by our attempts to harnessing student participation for curriculum design activities in undergraduate programmes with the Department of Geography at a UK university. As part of a broader curricular revision process proposed by the University, we sought students' input on how the curriculum was organised and how they saw the curriculum going forward. We organised both virtual and in-person activities to harness the student voice, by publishing a survey and conducting focus groups in which students assembled their own version of the curriculum. Despite our efforts to provide adequate incentives, including online shopping vouchers, we obtained minimal engagement from the student body. After informally inquiring to students the reason they were not taking part in the activities, students reported they were fatigued from the constant requests for feedback. They also reported that they thought participating in these student engagement activities distracted from their studies while providing little direct benefit, since they would not be affected by changes in the curriculum stemming from their own feedback.

Apparent in these responses is a tension between the positionalities and identities assumed of students within the current HE context. University students have - in government policy increasingly been presented as consumers who should engage in an instrumental manner with their degree studies in order to achieve the optimum individual benefit. In this sense, university students are expected to become strategic, instrumental citizens of their university for the duration of their studies. Simultaneously, the marketisation of the higher education sector in the UK - alongside efforts to monitor the 'quality' of teaching and learning within the sector have placed growing emphasis on the importance of student voice in quality assurance activities. At the same time, University's encourage students to feel a deeper sense of connection and community - of belonging - to the institution, and to become 'active' student- 
citizens of the institution. By 'active' what we mean here is that students not only feel a sense of belonging and affiliation, but that they engage with various practices of engagement actions which contribute to governance and quality assurance mechanisms within the institution, including various student voice activities. A tension, however, emerges: these actions require investments of time and energy on providing feedback and input which are unlikely to have direct benefit to the individual student participating in these activities. Thus, we see a clear tension between assumed/desired positionalities and practices of students (as citizens of a university), one which is exacerbated by the routinisation of - and orthodoxy surrounding - student voice.

To mobilise this provocation, we begin by reviewing debates relating to student engagement policy and practice before locating these within the UK's changing higher education context in the UK. Informed by these discussions, we draw from debates in development studies and citizenship studies to question the efficacy of the current obsession with student engagement, and whether this is experienced as a new tyranny of participation. From these we argue that while the promotion of student engagement is inspired by ideals of creating active learnercitizens, these ideals are challenged by the reality of strategic and instrumental learnercitizenship behaviours.

\section{Student engagement}

The idea that students can co-create their learning experiences is not new. In fact, co-production has been a defining factor in education theory in the last century, permeating Dewey's (1916) notion of progressive education, Rogers's principles of humanist education (Rogers and Freiberg, 1970) and Freire's ([1970] 2000) vision of transformative and participatory pedagogy. Critical pedagogies have long advocated for the collaboration between students and 
staff to challenge existing forms of teaching and co-create knowledge based on their own experiences, by encouraging "major shifts on the part of teachers, students, and researchers in relationships and in ways of thinking and feeling about the issues of knowledge, language, power, and self" (Oldfather and Dahl, 1995:87).

Through the influence of critical pedagogies the idea of democratised learning was extrapolated to incorporate the learning experience, giving rise to proposals for more active involvement of students in teaching governance (Cook-Sather, 2006). Drawing from the literature on critical pedagogies, Boomer (1992) focused on negotiating the curriculum as a mean of challenging existing power relationships within education. Similarly, Falchikov (1986) and Stefani (1998) proposed negotiating marking criteria and assessment formats with students in an effort to empower them to construct their own learning trajectory.

These critical pedagogical practices have been embraced by scholars and higher education institutions alike, but growing emphasis on the marketisation of higher education have emptied these practices of their political character (Zepke, 2018). Thus, while higher education literature has been flooded with participatory perspectives that advocate for students to play an active role in shaping their learning experience, this research makes little reference to its theoretical base in critical pedagogies. On the contrary, student engagement literature has moved away from the political nature of critical pedagogies to a more instrumental use of student voices, focusing on student retention and employability skills rather than the emancipatory ideals of critical pedagogies (Bovill, 2013b).

In practice, Universities have adopted the current concept of student engagement as a quality assurance measure. Thus, student engagement is often understood as "the extent to which students engage actively and measurably in learning, university and wider community activities", with effective student engagement often understood as associated with "a range of 
'positive' outcomes such as higher attendance and retention rates, examination and degree results, and employment rates" (Macfarlane and Tomlinson, 2017: 6). This instrumentalization of the student voice has shifted the role of the students from partners, as initially proposed in critical pedagogical theories, to objects of consultation, in which students engage with a fixedobject to provide data and have little power over the outcomes affected by their participation (Ashwin \& McVitty, 2015).

While optimists would argue the rise of student engagement initiatives shows the realisation of John Dewey's call for institutions to place student voices at the core of educational decisionmaking (Bovill, 2013a), others contend that efforts to promote student participation in governance and quality assurance are linked to the shifting higher education policy arena (Macfarlane and Tomlinson, 2017). These differing views are linked, in part, to the nebulous nature of the term 'student engagement' and its myriad uses, including - in the UK context as a proxy for quality teaching (Leach, 2016) and in relation to participation in governance and quality assurance (student voice).

The use of student voice as a proxy for quality teaching via student evaluations of teaching (SET) has a long history, predating recent concerns with the neoliberal turn within the higher education sector. While such practices are lauded for giving students' a voice in evaluating their teaching experience (see useful summary discussion in Moore and Kuol, 2005), concerns have been raised regarding the use of these metrics within probation and promotions processes (Hornstein, 2017), relating to influences on student perceptions (Santhanam and Hicks, 2002), that SETs encourage leniency in marking (Wang and Williamson, 2020), as discouraging innovative teaching (Harland and Wald, 2018), and in relation to (unconscious) bias amongst students when completing these activities - with evidence demonstrating that age, gender and BAME status influence student responses (see Reid, 2010; Smith, 2012). Nonetheless, SETs continue to be viewed as a key student voice activity - both by HE institutions, and understood 
as such by students themselves. The centrality of SETs as student voice is evidence in their prominence in ongoing curriculum development and planning activities, annual quality assurance reflections within and beyond Departments, academic staff promotion cases, and connections to student voice questions in NSS and other surveys.

\section{The UK's shifting higher education context}

The landscape of higher education in the UK has changed significantly over recent years, framed by evolving governmental priorities. One of the key drivers has been a funding model that has increasingly moved the cost burden of university education away from the public purse and on to individual students. This process began with the Teaching and Higher Education Act 1998 which introduced (maximum of $£ 1,000$ per year) tuition fees across the UK. The subsequent devolution of government to Scotland, Wales and Northern Ireland has led to a divergence in fee regimes in the intervening period. In England, the cost to students of university education has continued to rise - with maximum fees being raised to $£ 3,000$ by the Higher Education Act 2004 and then to $£ 9,000$ per year following the Browne Review in 2010. In 2019/20, Welsh students reading for a degree at a Welsh public university also pay up to $£ 9,000$ per year, while Scottish students attending a public university in Scotland pay up to $£ 1,820$ per year, and Northern Irish students studying at a public university in Northern Ireland pay up to $£ 4,160$ per year.

Allied to these changes has been the increased use of metrics to measure, quantify and evidence 'excellence'. In 2014, the Research Excellence Framework (REF) replaced the previous Research Assessment Exercise as a mechanism to measure the quality of research undertaken within universities. In 2016, the Higher Education Funding Council for England (HEFCE) introduced the Teaching Excellence Framework (TEF) to measure teaching excellence at an 
institutional level (Perkins, 2019). While significant concerns exist about the ability of the TEF to quantify and measure teaching excellence (Ashwin, 2017; Canning, 2019; Gunn, 2018; Matheson, 2019; Wood and Su, 2017), at the time of writing the Office for Students (OfS) is finalising the implementation of subject-level TEF. In seeking to quantify teaching excellence, the TEF utilises metrics relating to student retention rates, post-graduation employment and salary, and student satisfaction with teaching. Student satisfaction indicators are expected to utilise a subset of National Student Survey (NSS) questions relating to teaching, assessment and feedback, academic support, and - if the second pilot for subject-level TEF is an accurate guide - learning resources and student voice. The phrasing of the NSS questions relating to student voice ("I have had the right opportunities to provide feedback on my course", "Staff value students' views and opinions about the course", "It is clear how students' feedback on the course has been acted on", and "The students' union (association or guild) effectively represents students' academic interests") reinforces the argument that students are increasingly positioned as consumers within a marketized sector (Tight, 2013).

The positioning of students-as-consumers is evident in the discourse of "successive UK governments... [who] deploy prospective students as informed customers that will drive improvements in quality" (Buckley, 2018: 720). This discursive position is evident in various governmental Green and White papers and in justification for the introduction of - and subsequent dramatic increase in - student fees (Kelly et al., 2017; Tight, 2013). These developments reflect broader governmental efforts to reposition the purpose of higher education as being an individualised investment made to increase individual economic wealth, and thus stimulate overall economic growth, rather than as being a public/collective good (Kelly et al., 2017). Consequently, critics have argued, we have witnessed the increasing conception of undergraduate students as both consumers and as "individual entrepreneurs, 
transacting their way through higher education, preparing themselves for high-earning success in the global field of market competition" (Kelly et al., 2017: 106).

The UK has witnessed an increasing marketization of the HE sector, rising participation rates, universalisation of metrics to assess 'excellence', and governmental concerns with completion rates and levels of student achievement (Macfarlane and Tomlinson, 2017). These trends reinforce the positioning of the student-as-consumer, and the associated consumerist shift in relations between universities and students. This transactional consideration is reinforced through narratives surrounding the introduction of TEF (Perkins, 2019) as well as the focus of the NSS on student satisfaction (Carey, 2013). These developments, Kelly and colleagues (2017: 107, 110) argue, have repositioned the idea of an engaged student from being someone who would "strive to understand, contemplate and create the democratic conditions that enabled a set of shared social and cultural ideals to be realised" and towards being "an entrepreneurial homo economicus, who could maximise the return on their educational investment".

This trend underpins a set of paradoxical expectations relating to student voice: the positioning of the student as homo economicus and strategic consumer and university citizen, and the increasing requests and expectations for students to engage with and participate in processes of curriculum enhancement and evaluation for little or no direct individual benefit. Thus, on the one hand students are explicitly encouraged to be strategic student-citizens (who strategically invest in ways to get the best degree possible at the minimal individual cost/effort) while simultaneously being asked to be active student-citizens (participating in decisionmaking activities for no direct, individual benefit) (see also Kelly et al., 2017).

The recent emphasis on student engagement within the UK's HE-sector flows from these developments. Driven by governmental policies and papers, and positioned as a core aspect of 
quality assurance and enhancement practices (Buckley, 2018) student voice activities include module evaluation questionnaires, student representatives on Departmental and Faculty committees, and the involvement of students in curriculum and programme design activities. This heightened emphasis echoes both wider trends across the public sector to promote user involvement in planning and decision-making and the discursive positioning of students-asconsumers (Carey, 2013; Milburn-Shaw and Walker, 2017). Reinforcing these trends, research on student engagement and participation has often focused upon instrumental considerations which position students as astute and strategic decision-makers seeking to secure the optimum individual outcome. However, this positioning of students as consumers can be counterproductive for educational outcomes.

Self-identification by students as a service-user, even an active service-user as advocated in current student engagement practice, can be an obstacle towards development of academic citizenship and a group-based identity. Students' perceptions about their own roles in higher education determine how they approach learning (Barnett \& Coate, 2004), and students who perceive themselves to be consumers of education (rather than co-creators of their own learning) have poorer academic performance (Finney \& Finney, 2010). More importantly, identification as a consumer of education does not promote greater participation and involvement (Woodal, Hiller \& Resnick, 2013). Thus, Bergan (2004) argues that for students to contribute to the development of the higher education institution, they must have a civic rather than consumerist interest in the University - a positionality at odds with dominant policy discourse. Despite these obvious tensions, we are witnessing growing demands for student voice to be considered - not only through student evaluations of teaching, but in curriculum design and development, and beyond.

\section{The tyranny of student participation?}


As intimated above, our concern centres upon how demands for student voice have become universalised to the extent that we can understand these as a new orthodoxy, a received wisdom almost ritualistically rolled out (Zepke, 2014). Although in a very different sector - that of international development - Cooke and Kothari's argument (2001a) that participation had become a 'new tyranny' resonates strongly at this juncture.

Within the international development field, participatory development approaches were "represented as emerging out of the recognition of the shortcomings of top-down development approaches" (Cooke and Kothari, 2001b: 5). However, concerns with the ubiquitous and problematic adoption of participatory approaches to international development policy and practice in the 1990s led to a series of critical engagements and rejections of this approach including Cooke and Kothari's (2001a) edited collection Participation: The new tyranny? The opening pages of their book outline how a "participatory development establishment" entrenched "received wisdom about the overwhelming benefits of participation" while challenges and criticisms were ignored (Cooke and Kothari, 2001b: 1). In noting stories of "participatory processes [being] undertaken ritualistically, which had turned out to be manipulative" (Cooke and Kothari, 2001b: 1), Cooke and Kothari argued that the orthodoxy of participation was harmful to local communities and failed to deliver on stated aims.

Within the UK's HE sector, student participation within governance and quality assurance has been presented as a means to enhance student success, addressing shortcomings in curricula and student experience due to students being previously absent from decision-making processes. A clear resonance exists. Simply replace 'people' with 'student' in the following quote and Cooke and Kothari (2001b: 5) could be talking about UK universities instead of international development, "make 'people' central... by encouraging beneficiary involvement in interventions that affect them and over which they previously had limited control or influence" (Cooke and Kothari, 2001b: 5). 
We have seen that " $[\mathrm{g}]$ iving students more power in the decisions that affect their education has been celebrated by governments... has become central to quality assurance mechanisms, and 'student engagement' - understood in that way - has become a buzzword featuring in numerous policy documents, conference titles, institutional committees and job descriptions" (Buckley, 2018: 720). With student engagement being viewed as "the latest buzzword" (Gibbs, 2014), an accepted "'good thing' in higher education for researchers and policy makers" (Ashwin and McVitty, 2015: 343), and central to governmental white papers (e.g. Department for Business, Innovation \& Skills, 2011), it is clear that student voice has become an expectation and orthodoxy.

This process is evident in the ubiquitous requirement for student participation activities in curriculum development processes - as illustrated by our experiences outlined below - and reinforced through the inclusion of student voice within TEF metrics. These moves indicate that student participation/voice has emerged as a powerful orthodoxy in quality assurance and degree governance, providing clear parallels to the emergence of the orthodoxy of participation within the development sector (Cooke and Kothari, 2001a). Thus, student voice has evolved from buzzword to received wisdom, with primacy given to the assumed benefits of these activities with little cognisance given to the burdens such expectations can cause nor the depoliticization of these practices resulting from the routinisation of student voice requests. As Seale and colleagues (2015: 535) caution, "[t]he evaluation and feedback agenda has been subsumed as a component of student engagement and the reflective practice agenda has all but disappeared from policy discourse", reinforcing an agenda which eclipses reflexive-based practice and promoting performativity (see also Carey, 2013: 7).

To illustrate our concern with the ritualization of student voice activities, consider the following situation: 
Over the course of a 3-year undergraduate degree, a student takes 360 credits-worth of modules, divided up as 120 credits per year. Assuming these are taken as 6 twenty-credit modules per year, this amounts to 18 separate modules taken in total across the degree programme. According to best practice, students should be asked to complete a (light touch) mid-module evaluation activity, plus an end of module evaluation, amounting to 36 student voice 'events' over the three years of the programme. Students are also expected to complete end-of-level evaluation surveys, plus the National Student Satisfaction (NSS) survey in their final year. This totals 40 student voice events purely with a view to quality assurance. In addition, student representatives on the Departmental Staff-Student Committee (or equivalent) and the Departmental Teaching and Learning Committee ask for student input a further 8 times per year.

In this scenario, we experience 64 student voice events during a three-year degree programme, or 21 student voice requests per year - almost the equivalent to one per week (assuming 24 teaching weeks per year). These figures exclude less/in-formal student voice moments, as well as formal requests for curriculum development and programme design consultation, invitations which can mount up quickly if there is a concerted drive towards curriculum change: it was the difficulties encountered in eliciting student participation in undergraduate curriculumdevelopment that stimulated this article.

The central project discussed here was linked to a broader curriculum revision process referred to as the 'Programme Level Approach' (PLA). The PLA seeks to ensure a degree programme is experienced as a coherent and holistic journey, providing "students [with] opportunities to develop the deep knowledge, broad skills, and range of attributes they need to become assured and confident graduates" (The University of Sheffield, 2019). The first student voice activity implemented was a brief online questionnaire. Multiple email invitations were sent to over 400 
students over a period of 6-weeks, incentivised by an opportunity to win a £20 Amazon voucher upon completion of the questionnaire: 42 responses were received - a $10 \%$ response rate.

A series of focus group sessions were then organised to gain deeper insights from students on the strengths and weaknesses of the current curriculum, including a scenario modelling activity through which students were asked to design their ideal/preferred curriculum (within a basic set of rules - the programme must include 120 credits of modules per year, a dissertation component must be included at level 3). Students were encouraged to be creative and innovative in their responses. Invitations to participate were communicated via the Department, student society and student ambassadors, with an incentive of free food and session slots timetabled to avoid clashes with teaching activities. However, only one student signed-up. Consequently, the incentive was increased to a $£ 10$ Amazon voucher, resulting in two further students signing-up - a number increased by asking student ambassadors to participate, resulting in a total of seven students participating - a $1.7 \%$ participation rate.

Informal feedback from students who did not engage with these student voice activities identified a number of reasons for their resistance (Seale et al., 2015) to participating:

1. students felt they received an overwhelming number of emails requesting participation in student voice activities;

2. students recognised that they would not directly experience the benefits of investing time in such activities;

3. students felt that participation in these activities was time taken away from their studies and which would not contribute to their degree outcome.

Parallels are clear with Macfarlane and Tomlinson's (2017) argument that there is a danger of student engagement (with learning) being reduced to performativity, wherein students need to 
demonstrate 'active' learning in measurable ways. While their focus - and that of Gourlay (2015), who also utilises the term 'the tyranny of participation' - is upon student engagement with learning, rather than with governance, similar concerns exist. Concerns relating to performativity can be identified in relation to module evaluation and feedback processes, reflected in low response rates to these activities. Undoubtedly, part of the challenge is effectively communicating changes made in response to feedback - but even when this feedback loop is closed, the reality is that these changes do not affect the cohort providing feedback. Consequently, the oft-heard response from non-participating students is that it doesn't benefit me'. Such responses return us to the critique levelled by Seale et al. (2015), that within the student engagement agenda there remains little understanding of how students themselves feel about these developments - a critique again paralleling the criticisms of the participatory turn in international development (Cooke and Kothari, 2001a). Ultimately, student attitudes towards engagement activities illustrate the pervasive positioning of students as consumers and strategic investors (Bunce, Bairn \& Jones, 2017; Carey, 2013).

Our experiences, outlined above, correlate with these concerns and echo Seale et al.'s (2015) experiences in trying to deliver a Partnership in Education project. Their project, designed to influence how student voices were heard, faced significant challenges in recruitment, with low numbers of students engaging and efforts to mobilise students taking far longer than anticipated. Reflecting on their experiences, Seale et al (2015) suggest power dynamics may have contributed to these challenges, along with various practices of 'resistance'. While they acknowledge resistance was partly from staff, the primary form of 'resistance' related to the lack of student buy-in to the project - "the largest sign of resistance in this project was the fact that over 50 of the second-year students and 40 of the first-year students resisted taking part in any aspect of the project, despite our best efforts" (Seale et al., 2015: 548). Adopting this 
phrasing of 'resistance', our experience is even more damning - with over $90 \%$ of the undergraduate student body resisting taking part.

The reasons for this lack of engagement, elicited through informal feedback and conversations with students, resonate strongly with Seale et al.'s (2015: 548) experiences which they categorise as "students felt that they could not afford to volunteer to give time to something that would not 'count towards their degree'. Perhaps they had 'voice fatigue'... Perhaps we were wrong to presume that students would want to have a voice in their programme?" The repetition of the same messages from our students suggests this is a growing challenge - as student voice activities are increasingly routinized, they become not only increasingly depoliticised and mechanical but also led to resentment and disengagement.

Our students certainly spoke in terms of voice fatigue - and understandably so when you consider how often they are asked for input. But more than this, their responses spoke clearly to a frustration of being positioned as consumers/investors who need to prioritise their degree but also then being repeatedly asked to invest time and energies in voice activities which would not provide any direct benefit to them. Thus, despite efforts close the feedback loop students clearly recognised that the benefits were for future cohorts. Exacerbating this situation was a sense that the routinisation of student voice requests led to these being viewed as superficial and performative moments of engagement, rather than transformative (see Fielding, 2004).

Thus, we began to see that students identified that the increasing numbers of student voice requests offered no direct benefits to them (as individual, strategic student-citizens of the university), while providing longer-term benefits to the institution. The positioning of students as strategic, instrumental citizens of the university has the corollary effect of reducing the concomitant longer-term stake in the future health of the university as the sense of belonging and identity is increasingly aligned to securing individualised, short-term benefits (for parallel 
debates in citizenship studies see Harpaz and Mateos, 2019; Joppke, 2019). The orthodoxy to seek student voice therefore runs counter to, and sits in tension with, this positioning to create a strategic/instrumental active student-citizen paradox.

\section{The strategic active student-citizen paradox}

This paradoxical positionality relates to the third dimension of student engagement identified by Trowler and Trowler (2010): student identity. This aspect speaks to the relational aspect of student engagement, of how a sense of being is central to students' engagement with their disciplines and construction of their own educational experiences (Solomonides and Reid, 2009). Barnett and Coate (2004) extend this concept, framing identity and a sense of being as indispensable in the learning process. They argue that the role of higher education is developing students as people, and thus encouraging the development of their own self-concepts. Recognising the disparity between students' 'actual' identities and the identities that are designated to them - as consumers, as partners - is necessary to promote student engagement and to facilitate their own exploration of what that disparity could represent (Crick, 2012). More pertinently, is the need to consider how efforts to encourage student voice are expected to both promote and result from students' sense of identity as a part of the university. Thus, Buckley (2018) argues that efforts to realise effective student voice can be understood through Sherry Arnstein's ladder of participation, suggesting that efforts to enhance student voice are expected to improve teaching quality and excellence and to ensure learners feel and act like active, engaged citizens of the university.

From this starting point, student identity can be understood as a form of citizenship at the scale of the University. Not only do "universities serve as a locus of citizenship production and consumption" (Cheng and Holton, 2019: 614), but they are themselves locations of belonging 
and citizenship. In making this argument, we recognise that citizenship exists at multiple scales and an individual may hold multiple citizenships simultaneously (Sejersen, 2008; Harpaz and Mateos, 2019; Joppke, 2019) but also that it is important to recognise the "grounding [of] citizenship experiences in the actual sites and spaces where their meanings are produced" (Cheng and Holton, 2019: 614).

Working with Osler and Starkey's (2005) understanding of citizenship as comprising status, feeling and practice, we understand student-citizenship (at the University scale) as identified by registration as a student at a university (status), as sense of identity, belonging and affinity which is encouraged in connection to degree, academic Department, Student Union, etc (feeling), and as conduct allied to codes of conduct and engagement with learning and teaching and student voice activities (practices). In adopting this approach, we differentiate our concern from work elsewhere which has talked of student/learner-citizens in terms of efforts to construct young people as 'good' national citizens (e.g. Bayly, 2014; Hammett and Staeheli, 2013; Moser, 2016) or as cosmopolitan, global citizens (e.g. Pashby, 2011). Instead, we rescale the notion of citizenship to the university as a particular form of (temporally discrete) local citizenship. Working from this framework, we understand how expectations surrounding student engagement and voice intersect with tensions between ideal and actual modes of learner-citizenship - a set of tensions that originate, in part, from the conflicted overarching policy narratives. Thus, we argue, we are witnessing a trend towards instrumental-strategic attitudes towards student-citizenship which result in thin practices of citizenship that prioritise individual over collective benefit (more broadly, see Adim, 2017; Bauböck, 2019; Harpaz and Mateos, 2019; Joppke, 2018). In turn, this leads to a key question: why would a student want to engage in governance practices within universities?

For some students, involvement as representatives reflects an underlying political or moral belief. For others it may be a strategic, CV-boosting activity to undertake. More generally the 
assumption seems to be that students will want to be 'partners' and thus participate in student voice activities because they feel an affiliation with and identify as a member of the University community - a student-citizen who will then actively undertake actions/practices associated with this status and which contribute to the future health of the institution. However, the realities differ markedly as students are increasingly positioned (and position themselves) as strategic/investor student-citizens seeking to ensure maximised individual benefit.

Drawing from Carey's (2013) interpretation of Fielding's 4-fold typology of student voice and engagement, we can see each form of voice activity has a cost to students while also becoming routinized and depoliticised. Starting with student voice as data source (i.e., completing module and level evaluations), while the cost per action is relatively limited - a few minutes - the frequent, routinized nature of this activity plus lack of direct benefit to the student completing the activity becomes problematic. Seeking to involve students as active respondents (being consulted about changes) can have varying time costs associated, depending on the activity undertaken, but again has become ritualised within curriculum development activities and rarely has direct benefit to a participating student. As we move into students as co-researchers and as researchers, the time demands upon these students' increases dramatically with little direct benefit for the students' degree experience and outcome. Such practices ask students for a short-term input to contribute to a deferred benefit (one which the student is unlikely to see direct benefit from). Thus, there is an assumption that students identify as active studentcitizens while they are simultaneously encouraged to act as strategic student-citizens, making decisions and investments to ensure the best degree outcome for themselves.

This returns us again to the question of why do we assume students want to participate in governance and quality assurance practices (Seale et al., 2015) given the costs of such actions. As Carey (2013: 75) observes, "[t]here is little debate given to the burden of extra work and responsibility for course representatives. Yet, they are expected to sit on an ever-growing range 
of committees, review documentation and act as a medium through which messages are relayed to the rest of the student body." Not only is the received wisdom of student voice is clearly driving these processes, but this is further skewing the cost-benefit equation and - ironically further encouraging students to be strategic, instrumental student-citizens rather than active student-citizens.

Thus, whilst student engagement and participation in University governance processes has been shown to encourage the development of a sense of identification with the institution (Freeman, 2013), thus contributing to the creation of a stronger collective identity and promoting further engagement. However, for this to be effective we need to ensure that requests for student voice are not routinized and treated as an orthodoxy. The tyranny of ubiquity actually undermines engagement and solidarity. A more critical reflection upon the frequency, intensity and form of student voice activities is needed to ensure these are both viewed as - and do - lead to meaningful engagement and change, as well as contributing to a robust collective identification as a member of the university community. The current operationalisation of student engagement focuses on behavioural engagement rather than the other dimensions that encompass a sense of citizenship within an academic community (Mahon \& Portelli, 2004). Thus, the risk exists of the practice of engaging with routinized student voice activities simply being a ritualised performance to be completed, but one which is rendered meaningless without a sense of belonging that fosters the collective identity and commitment to the shared future of the programme/Department. In other words, routinized forms of voice may contribute to students' disengaging from the university community, further reducing a student's interest in the (self)governance of the institution and its membership (see Spiro, 2019).

\section{Conclusions}


As with Cooke and Kothari (2001b), we are aware that a challenge to dominant orthodoxy and powerful institutions and individuals may not endear us to those role-holders. Whereas Cooke and Kothari (2001b: 4) ultimately utilise the term 'tyranny' to reflect upon how participatory development approaches facilitate the "illegitimate and/or unjust exercise of power", our intention is more modest. Our concern is to question the rationale for and viability of the received wisdom of student engagement, and the orthodoxy surrounding the practices of this. Ultimately, we explore the paradox of the strategic active student citizen as is imagined existing at the intersection of the positioning of students as strategic consumers, while simultaneously expecting their participation in university/degree governance practices. The upshot of these processes is an inherent tension between promoted and expected modes of student-citizenship that come to the fore in relation to student participation requests.

As outlined at the start of the paper, the motivation for this paper arose from continued struggles to secure student participation in curriculum development activities, and the response from students that they were a) suffering from fatigue in the face of multiple participation requests, and b) making strategic decisions to prioritise activities that would enhance their degree outcomes. This sense of fatigue illustrates how ubiquitous and routinized requests for 'student voice' have become - a new orthodoxy. The received wisdom that student voice must be sought and students actively want to participate is experienced - at times - as a tyranny by staff who seek (in vain) to engage students with these activities, but also by students who feel bombarded by such requests.

Moreover, the orthodoxy of student participation sits in tension with the positioning of students-as-consumers. As we outline above, there is a tension between on the one hand the positioning of students as strategic, instrumental members - or citizens - of the university, who have limited vested or shared interest in the organisation's future and who are expected to make decisions to prioritise their own degree outcomes. On the other hand, the expectations of 
student participation assume students will be active citizens of the university, not only adhering to the regulations of the institution but committing time and energies to participation activities which will have deferred benefits for future student cohorts and for the longer-term benefit of the institution. These competing imperatives produce the paradox of the strategic-active student-citizen, one who is beset by routinized demands for engagement and participation. 


\section{Declaration of Interest}

There are no conflicts of interest to declare.

\section{References}

Adim, Leila. 2017. 'Between benefit and abuse: immigrant investment programs'. Saint Louis University Law Journal 62 (1): 121-136

Ashwin, Paul, and Debbie McVitty. 2015. 'The Meanings of Student Engagement: Implications for Policies and Practices'. In The European Higher Education Area, edited by Adrian Curaj, Liviu Matei, Remus Pricopie, Jamil Salmi, and Peter Scott, 343-59. Cham: Springer International Publishing. https://doi.org/10.1007/978-3-319-20877-0_23.

Ashwin, Paul. 2017. 'What Is the Teaching Excellence Framework in the United Kingdom, and Will It Work?' International Higher Education, no. 88 (January): 10-11. https://doi.org/10/ggxvc3.

Barnett, Ronald and Kelly Coate. 2005. Engaging the Curriculum in Higher Education. SRHE and Open University Press Imprint. Open University Press. https://books.google.be/books?id=aEop96rzaRMC.

Bauböck, Rainer. 2019 'Genuine links and useful passports: evaluating strategic uses of citizenship'. Journal of Ethnic and Migration Studies 45 (6): 1015-1026

Bayly, Susan. 2014. 'How to Forge a Creative Student-Citizen: Achieving the Positive in Today's Vietnam'. Modern Asian Studies 48 (3): 493-523. https://doi.org/10/f5zcwk. Bergan, Sjur, ed. 2004. "Higher education governance and democratic participation: the university and democratic culture”. In The University as Res Publica: Higher Education Governance, Student Participation and the University as a Site of Citizenship. Council of 
Europe Higher Education Series / Council of Europe 1. Strasbourg: Council of Europe Publ.

Boomer, Garth. "Negotiating the curriculum reformulated." Negotiating the curriculum: Educating for the 21st century (1992): 276-289.

Bovill, Catherine. 2013a. 'Students and Staff Co-Creating Curricula: An Example of Good Practice in Higher Education'. In The Student Engagement Handbook: Practice in Higher Education, edited by Elisabeth Dunne and Derfel Owen, First edition. United Kingdom: Emerald.

Bovill, C. 2013b. 'Students and Staff Co-Creating Curricula: A New Trend or an Old Idea We Never Got around to Implementing?' In Improving Student Learning Through Research and Scholarship: 20 Years of ISL, edited by C. Rust, 96-108. Improving Student Learning 20. Oxford, UK: Oxford Centre for Staff and Learning Development.

Buckley, Alex. 2014. 'How Radical Is Student Engagement? (And What Is It For?)'. Student Engagement and Experience Journal 3 (2). https://doi.org/10/ggd8k2.

Buckley, Alex. 2018. 'The Ideology of Student Engagement Research'. Teaching in Higher Education 23 (6): 718-32. https://doi.org/10/ggd8k3.

Bunce, Louise, Amy Baird, and Siân E. Jones. 2017. 'The Student-as-Consumer Approach in Higher Education and Its Effects on Academic Performance'. Studies in Higher Education 42 (11): 1958-78. https://doi.org/10/ggd8k5.

Canning, John. 2019. 'The UK Teaching Excellence Framework (TEF) as an Illustration of Baudrillard's Hyperreality'. Discourse: Studies in the Cultural Politics of Education 40 (3): 319-30. https://doi.org/10/gcz7rv.

Carey, Philip. 2013. 'Representation and Student Engagement in Higher Education: A Reflection on the Views and Experiences of Course Representatives'. Journal of Further and Higher Education 37 (1): 71-88. https://doi.org/10/fzr8w2. 
Cheng, Yi'En, and Mark Holton. 2019. 'Geographies of citizenship in higher education: an introduction'. Area 51 (4): 613-617.

Cook-Sather, Alison (2006). 'Sound, Presence, and Power: "Student Voice” in Educational Research and Reform'. Curriculum Inquiry 36 (4): 359-390. https://doi.org/10/10.1111/j.1467-873X.2006.00363.x

Cooke, Bill, and Uma Kothari, eds. 2001a. Participation: The New Tyranny? London ; New York: Zed Books.

Cooke, B., and U. Kothari. 2001b. 'The Case for Participation as Tyranny'. In Participation: The New Tyranny?, 1-15. Zed Books.

Crick, Ruth Deakin. 2012. 'Deep Engagement as a Complex System: Identity, Learning Power and Authentic Enquiry'. In Handbook of Research on Student Engagement, edited by Sandra L. Christenson, Amy L. Reschly, and Cathy Wylie, 675-94. Boston, MA: Springer US. https://doi.org/10.1007/978-1-4614-2018-7_32.

Department for Business, Innovation \& Skills. 2011. Students at the Heart of the System. Dewey, John. 1916. Democracy and education: An introduction to the philosophy of education. New York: The Macmillan Company.

Falchikov, N., 1986. 'Product comparisons and process benefits of collaborative peer group and self assessments', Assessment and Evaluation in Higher Education, 11(2), pp.146166.

Fielding, Michael. 2004. 'Transformative Approaches to Student Voice: Theoretical Underpinnings, Recalcitrant Realities'. British Educational Research Journal 30 (2): 295-311. https://doi.org/10/b6bpq8.

Finney, Treena Gillespie, and Zachary R. Finney. 2010. 'Are students their universities' customers? An exploratory study'. Education and Training 52 (4): 276-291. https://doi.org/10.1080/0260293860110206 
Freeman, Rebecca. 2013. 'Student Engagement in Practice: Ideologies and Power in Course Representation Systems'. The Student Engagement Handbook: Practice in Higher Education, 587-600.

Freire, Paulo. (1970) 2000. Pedagogy of the Oppressed. New York: Continuum.

Gibbs, Graham. 2014. 'Student engagement, the latest buzzword'. Times Higher Education 1 May 2014. Accessed $21^{\text {st }}$ November 2019 at https://www.timeshighereducation.com/news/student-engagement-the-latestbuzzword/2012947.article

Gourlay, Lesley. 2015. “'Student Engagement” and the Tyranny of Participation'. Teaching in Higher Education 20 (4): 402-11. https://doi.org/10/gfw6xz.

Gunn, Andrew. 2018. 'Metrics and Methodologies for Measuring Teaching Quality in Higher Education: Developing the Teaching Excellence Framework (TEF)'. Educational Review 70 (2): 129-48. https://doi.org/10/ggd8k6.

Hammett, Daniel, and Lynn Staeheli. 2013. 'Transition and the Education of the New South African Citizen'. Comparative Education Review 57 (2): 309-31. https://doi.org/10/ggd8k7.

Harland, Tony, and Navé Wald. 2018 'Vanilla teaching as a rational choice: the impact of research and compliance on teacher development', Teaching in Higher Education, 23(4): $419-434$

Harpaz, Yossi, and Pablo Mateos. 2019. 'Strategic Citizenship: Negotiating Membership in the Age of Dual Nationality'. Journal of Ethnic and Migration Studies 45 (6): 843-57. https://doi.org/10/ggd8k8.

Hornstein, Henry. 2017. 'Student evaluations of teaching are an inadequate assessment tool for evaluating faculty performance', Cogent Education, 4(1), https://www.tandfonline.com/doi/full/10.1080/2331186X.2017.1304016. 
Joppke, Christian. 2019. 'The Instrumental Turn of Citizenship'. Journal of Ethnic and Migration Studies 45 (6): 858-78. https://doi.org/10/ggd8k9.

Kelly, Paul, Nic Fair, and Carol Evans. 2017. 'The Engaged Student Ideal in UK Higher Education Policy'. Higher Education Policy 30 (1): 105-22. https://doi.org/10/f9x8d8. Leach, Linda. 2016. 'Enhancing Student Engagement in One Institution'. Journal of Further and Higher Education 40 (1): 23-47. https://doi.org/10/ggd8md.

Macfarlane, Bruce, and Michael Tomlinson. 2017. 'Critical and Alternative Perspectives on Student Engagement'. Higher Education Policy 30 (1): 1-4. https://doi.org/10/ggd8mf. McMahon, Brenda J., and David Zyngier. 2009. 'Student Engagement: Contested Concepts in Two Continents'. Research in Comparative and International Education 4 (2): 164-81. https://doi.org/10/dj656q.

Matheson, Ruth. 2019. 'In Pursuit of Teaching Excellence: Outward and Visible Signs of Inward and Invisible Grace'. Teaching in Higher Education, April, 1-17. https://doi.org/10/ggd8mg.

Milburn-Shaw, Heather, and David Walker. 2017. 'The politics of student engagement'. Politics 37 (1): 52-66. https://doi.org/10.1177/0263395715626157

Moore, Sarah, and Nyiel Kuol. 2005. 'Students evaluating teachers: exploring the importance of faculty reaction to feedback on teaching', Teaching in Higher Education, 10(1): 57-73

Moser, Sarah. 2016. 'Educating the nation: shaping student-citizens in Indonesian schools'. Children's Geographies 14 (3): 247-262

Oldfather, Penny, and Karin Dahl. 1994. 'Toward a Social Constructivist Reconceptualization of Intrinsic Motivation for Literacy Learning'. Journal of Reading Behavior 26 (2): 13958. https://doi.org/10/ck6vt4.

Osler, Audrey, and Hugh Starkey. 2005. Changing Citizenship: Democracy and Inclusion in Education. Maidenhead: Open University Press. 
Pashby, Karen. 2011. 'Cultivating Global Citizens: Planting New Seeds or Pruning the Perennials? Looking for the Citizen-Subject in Global Citizenship Education Theory'. Globalisation, Societies and Education 9 (3-4): 427-42. https://doi.org/10/bcvhfw. Perkins, Graham. 2019. 'The Teaching Excellence Framework (TEF) and Its Impact on Academic Identity Within A Research-Intensive University'. Higher Education Policy 32 (2): 297-319. https://doi.org/10/ggd8mj.

Reid, Landon. 2010. 'The role of perceived race and gender in the evaluation of college teaching on RateMyProfessors.Com'. Journal of Diversity in Higher Education, 3(3): $137-152$

Rogers, Carl R, and HJ Freiberg. 1970. Freedom to Learn. New York: McMillan Publishing. Santhanam, Elizabeth, and Owen Hicks. 2002. 'Disciplinary, Gender and Course Year Influences on Student Perceptions of Teaching: Explorations and implications', Teaching in Higher Education, 7(1): 17-31

Seale, Jane, Suanne Gibson, Joanna Haynes, and Alice Potter. 2015. 'Power and Resistance: Reflections on the Rhetoric and Reality of Using Participatory Methods to Promote Student Voice and Engagement in Higher Education'. Journal of Further and Higher Education 39 (4): 534-52. https://doi.org/10/ggd8mk.

Sejersen, Tanja Brøndsted. 2008. "'I Vow to Thee My Countries” - The Expansion of Dual Citizenship in the 21st Century'. International Migration Review 42 (3): 623-49. https://doi.org/10/cpg8tw.

Smith, Holly. 2012. 'The unintended consequences of grading teaching', Teaching in Higher Education, 17(6): 747-754

Solomonides, Ian, and Anna Reid. 2009. 'Understanding the Relationships between Student Identity and Engagement with Studies'. In The Student Experience, 388-397. Higher Education Research and Development Society of Australasia. 
Spiro, Peter J. 2019. 'The Equality Paradox of Dual Citizenship'. Journal of Ethnic and Migration Studies 45 (6): 879-96. https://doi.org/10/ggd8mm.

Stefani, L.A., 1998. Assessment in partnership with learners. Assessment \& Evaluation in Higher Education, 23(4), pp.339-350. https://doi.org/10.1080/0260293980230402

The University of Sheffield. 2019. "Programme Level Approach", Accessed 15th November 2019. https://www.sheffield.ac.uk/staff/learning-teaching/our-approach/programmelevel.

Tight, Malcolm. 2013. 'Students: Customers, Clients or Pawns?' Higher Education Policy 26: 291-307.

Trowler, Vicki, and Paul Trowler. 2010. 'Student Engagement Evidence Summary'.

Wang, Guannan, and Aimee Williamson. (2020) Course evaluation scores: valid measures for teaching effectiveness or rewards for lenient grading?, Teaching in Higher Education, DOI: $10.1080 / 13562517.2020 .1722992$

Wimpenny, Katherine, and Maggi Savin-Baden. 2013. 'Alienation, Agency and Authenticity: A Synthesis of the Literature on Student Engagement'. Teaching in Higher Education 18 (3): 311-26. https://doi.org/10/ggd8mp.

Wood, Margaret, and Feng Su. 2017. 'What Makes an Excellent Lecturer? Academics' Perspectives on the Discourse of “Teaching Excellence” in Higher Education'. Teaching in Higher Education 22 (4): 451-66. https://doi.org/10/ggd8mn.

Woodall, Tony, Alex Hiller, and Sheilagh Resnick. 2014. 'Making Sense of Higher Education: Students as Consumers and the Value of the University Experience'. Studies in Higher Education 39 (1): 48-67. https://doi.org/10/brqc.

Zepke, Nick. 2014. 'Student Engagement Research in Higher Education: Questioning an Academic Orthodoxy’. Teaching in Higher Education 19 (6): 697-708. https://doi.org/10/ggd8mr. 
Zepke, Nick. 2018. 'Student Engagement in Neo-Liberal Times: What Is Missing?' Higher Education Research \& Development 37 (2): 433-46. https://doi.org/10/ggs5k8. 